\title{
Towards a contemporary drawing of the city
}

\author{
P. J. Juan Gutiérrez \& A. Martínez Medina \\ University of Alicante, Spain
}

\begin{abstract}
The way to understand the city, the diffuse and social significance in which the "bip" (b-elongings, i-nformation, p-eople) exchange system takes place is inevitably reflected in the drawing of the city. From drawings of the territory to those of the building, the architect has been striving to document that physical reality, traditionally understood as the essence of the urban fact. This communication investigates the way that contemporary calls to drawing incorporate tools of temporality and the social fact rather than the traditional material space that both have strived to represent. On the basis of the analysis of old plans, and continuing with the analysis of the possibilities of digital tools, the authors develop a discourse that positions the drawing as a carrier of information, which is not only spatial but also temporary. This fact attests what Ilya Prigogine has strived to assert: the irreversibility of the process (in this case the drawing), which will play a key role in the new strategy for the graphics, with which to understand a series of overlapping (and irreversible) discourses.

The conclusions of the work are intended to lay the groundwork for understanding and ordering, in an exercise in taxonomy, new ways (digital or not) to represent the urban reality. The absence of the validity of a single discourse generates not only a narrative script of multiple layers but, at the same time, the dependence between the different databases (from which come the drawings) and disciplines which end up defining them. Contemporary drawing of the city, always incorporating a temporary position, extends multidisciplinary bridges to exceed, by far, the mere representation of the physical fact.
\end{abstract}

Keywords: graphic expression, photogrammetry, GIS, teaching innovation.

\section{Introduction}

The way to understand the city, the diffuse and social significance in which the "bip" (b-elongings, i-nformation, p-eople) exchange system takes place (Ascher 
[1]), has invariably gone through work on its drawing. From drawings of the territory to those of the building, the architect has been striving to document that physical reality, traditionally understood as the essence of the urban fact.

This communication investigates the way that contemporary calls to drawing incorporate tools of temporality and the social fact rather than the traditional material space that both have strived to represent. On the basis of the analysis of old plans, and continuing with the analysis of the possibilities of digital tools, the authors develop a discourse that puts the drawing as a carrier of information, which is not only spatial but also temporary. This fact attests what Prigogine has strived to assert [2]: the irreversibility of the process (in this case the drawing), which will play a key role in the new strategy for the graphics, with which to understand a series of overlapping (and irreversible) discourses.

The conclusions of the work are intended to lay the groundwork for understanding and ordering, in an exercise in taxonomy, new ways (digital or not) to represent the urban reality. The absence of the validity of a single discourse generates not only a narrative script of multiple layers but, at the same time, the dependence between the different databases (from which come the drawings) and disciplines which end up defining them. Contemporary drawing of the city, always incorporating a temporary position, extends multidisciplinary bridges to exceed, by far, the mere representation of the physical fact.

\section{Research targets}

The aim of the present research work can be summarized in three main lines of thought:

1. Temporality: to argue that the consideration of the temporary component of the drawing of the city (and more specifically the irreversibility) is the guarantee of a mature contemporary expression.

2. Contemporary drawing: comparison of the analysis of traditional plans with the analysis of contemporary maps of the city and the territory with the intuition, formalized in a hypothesis, of detecting the problems faced by the current graphic expression.

3. Graphical criteria: to establish a valid and effective method for the evaluation of new ways (digital or not) of urban reality.

\section{Methodology}

Before starting the development work itself, we lay the argumentative bases in each work context. Therefore:

\subsection{First context: temporality}

Based on our own previous studies of temporality, we summarize the main starting points:

- We adopt the triad, a classification of temporality, presented by Ricoeur [3]: historical time (in the fissure between) phenomenological time and cosmological time. 
- Architecture request narrative as an essential part of historical time as long as that artifice (halfway between moving out and moving in that).

- The architecture is action, as long as it is inhabited.

- Time humanizes architecture (because time deteriorates, makes material and techniques imperfect, as does the human condition).

- The movement in phenomenological time involves movement of cosmological time, and vice versa, and a reconfiguration of historical time. Architecture, as in terms of social status, is an active part of this process.

\subsection{Second context: contemporary types of drawing}

Following a summarized criteria to expose ideas, we can list:

- Contemporary graphic expression, in its significance, may include traditional graphic expression.

- There is a new way of understanding the graphics derived from the ability of computers. For example, databases with point clouds, understood as final graphics, are a sign that the line has given way to the point in the digital environment.

- The purpose and need, mainly, mark guidelines to establish the validity of the tools to use (digital or not).

\subsection{Third context: graphical criteria}

In the theoretical field and, more specifically, in the field of architectural criticism in a graphics context:

- The purpose of the graphic criteria must be to set patterns for itself, i.e. even before the reflection and analysis of the graphics, it should establish the goals of the same (aside from that of the graphics).

- Derived from the previous necessity (the establishment of targets for criticism), we will be able to define a strategy for approaching the graphic criteria (digital or not).

- The figures of the critic and drawer must be reconfigured in each context with the aim of establishing the guidelines for the critical process that has been modified with the digital decentralization of graphical information.

\section{Discussion}

The key, as we see, will involve the organization of information since the database has become, for by shared and accessible, part of an after-problem. Let us take this example: the criterion for selecting digital content is, actually, one of the challenges faced by the artist (and by extension by the critic). To continue, we will deploy a series of analyses structured around a classification of drawings, namely:

1. Analysis drawings

- Physical;

- $\quad$ Ultra-physical (temporarily social);

- Others. 
2. Suggested drawings

- Physical;

- $\quad$ Ultra-physical (temporary);

- Others.

3. Hybrid drawings.

\subsection{Drawings taken as analysis}

Analysis drawings are confronted with documentation of what exists in the most objective manner possible. Each imaging technique, somehow associated with a particular form of encoded reality, is (or should be) used, in this type of work, as a starting point to the documentation of a series of associated databases.

\subsubsection{Physical}

This type of drawings is limited to developing the aspects of reality that can be understood and visually apprehended. Thus, graphic documents, containing information of the morphology (and materiality) of the parts which compose the city, arise.

\subsubsection{Ultra-physical (social due to temporality)}

We find drawings that represent an analysis of encoded reality (reality is always simplified and then encoded to be represented), not only of its spatial and material aspects. This way they become part of the graph, not only a georeferenced database but also the entire series of associated features (historical relationship and impact, subjective perceptions - either of an isolated individual or a group - and so on). The drawings emphasize everything but the drawing regarding the position of the materials.

\subsubsection{Others}

If we have, on the one hand, a section where we met all the physical aspects and, on the other, the rest of the drawings... what fits in the third section called "others"? Well, in this third section they join all the non-traditional graphics (but which respond to the representation of a particular analysis of reality), namely and for example, the text and its associated narration as well as the symbolism of a coherent but personal drawing.

\subsection{Drawing proposals}

By "drawing proposals" we understand graphic proposals that are not limited to encoded reality but that included (in transmitting contents) subjective concepts, in a general way. Either in one direction or the other (from or towards reality) the purpose is to incorporate information, in the form of proposals, on the basis of representation.

\subsubsection{Physical}

It is the type of graphic that traditionally has been identified architecture projects understanding them as proposals of the reality. The drawings often show a reality imagined but non-existent. 


\subsubsection{Ultra-physical (social due to temporality)}

The proposal that goes beyond the material space, regardless of the tools with which it is built, uses as tools of drawing the same point, line and plane.

\subsubsection{Others}

This type of drawing arises when using other than one's own (and traditional) symbols of the graphics, different from the existing structures and mechanisms, is proposed.. The encoding of a narrative (with its implicit fiction) can also be performed with the help of traditional drawings, but it is put in language tools (texts and symbols) when the result stands at the edge of the graphic.

\subsection{Hybrid drawings}

It is difficult to find a drawing representing the reality that does not propose information and vice versa, that suggesting new ways that may affect inhabiting do not encode the existing ones (drawings). The reality, as a hybrid as well as imperfect, teaches us that it doesn't exist the perfect, clear and unidirectional drawing. It is in this sense that we affirm that all drawings are hybrids in practice, although, possibly, they are not in their origin. On the one hand, to represent reality with a particular technique, we (the drawer and the reader) are focusing on a certain way of decoding the spelling as well as limiting (and, therefore, suggesting) the scope of such representation. On the other hand, when we project an intervention on the real (note that there is no project that can be understood from this concept of intervention, even in the desert or denying the environment, taking into account the context), even then we say that there is a way to develop graphic information from the existing reality and, therefore, analyse it.

In addition to the three contexts that we analyse (temporality, architectural criticism and contemporary graphics), and the types of drawings that we will introduce in each of them (analysis and proposals, physical or otherwise), we can include, before continuing with the main argument of the work, an additional reflection rarely seen in the drawings relating to the city: the absence of a limitation scale.

Both from a territorial point of view and from an objective point of view, the city and its problems (human habitation and what it implies) lack their own territory of action, out of which no consideration makes sense. Answer these two questions:

I. Where does an object end?

II. Where does the city begin?

Both questions have risen so consciously opposed, doubtful about the end of one term and the beginning of a different one. The first of them, the one related to limits (because an ontology of the end without the own one of the principle cannot be considered) of the object can begin to answer on the basis of the analysis of a particular object, but also, generalizing to another abstract one.

An object, for example an old wooden chair... does it really end up in the limits proposed by its physical materiality? Possibly, if we had to respond according to the parameters of the material (which in the classification of the drawings we have 
called the "physical"), we would have to answer affirmatively. The issue is that, as we have seen, reality drawing approaches are enriched by having not only the material part. In the case of an object, e.g. a chair, first we can speak of the material space of the same and, secondly, the physical space impact. This last, the area contaminated by the influence or impact of the object, far exceeds the material limits of the same. A committed and current representation of an object may need a different scale than that derived from the study of its materiality, and possibly associated with elements of a larger dimension...even, why not, on a proper scale for the territory. Relations, linkages between the elements will determine the necessary graphic (and scale) in each specific case. The common denominators, that is, the generator and the cause of this case study (casuistry), are linked with the human being as insofar as being social and temporal. To continue with the previous example, the wooden chair could be the subject of a map of the territory of the same impact. Its origin, its means of transport, agents that transform it and which it commercializes... etc., could be part of a map with the object as a rotor. Unusual drawings, like the paths of the people, of the waste...etc. All these maps far exceed the traditional representation of the same, say, at a level of $1 / 5$. It is in this way that we respond to the question about the limits of the object with a conditional sentence: the limits of the object do not have much to do with the inert reality as with the random characteristics of our world.

To the second of the issues, which invites us to reflect on the origin (referring to space, that is susceptible to graphic representation) of the city, it can be responded to with a sort of answer symmetrical to the above reflections. It all depends, as the reader must have already realized, on the intention and point of view of the city projects. Or, what is the same, what we understand by 'city'. How do we define it? In any case, the city, inseparably linked to the social temporal dimension, is a complex entity that can hardly be accurately considered during a graphic and/or textual coding. The beginning of the city and the beginning of the social being have a common denominator: the temporality linked to any kind of narrative. We can put forward an eloquent example derived from the use of geographic information systems (GIS), that kind of tool that organizes the information (geo) spatially. Traditionally understood as a tool of urban analysis (and proposed), they tend to be used in the representation of large tracts of land, ie blocks or urban island as part reference base. In addition, this type of organizational mechanism can serve to organize information on a territorial, urban, object, or microscopic scale. We could apply, for example, the proposal implied in the GIS to monitor geo-referenced positions of the various mechanisms of metal (for example) of a public building. The position that an object occupies on the surface of the Earth is, actually, a position relative to the number of objects, to which you connect it; without them, the geo location information makes no sense. For this reason we advocate that, when the geographic information systems are used on a territorial scale, really, this is because they are organizing information from a number of similar elements. The scale, in this sense, is relative. The beginning of the city, understood as a social organization, is a subjective issue depending on our goals and our needs. 
In the same way that the object can be drawn as a city, the city can be drawn in an object key. A chair can serve as a bridge to build the (spatial and temporal) relations, which have traditionally been studied at a territorial level. In the same way that a city can begin to be drawn and codify a series of objects, -composing it or not- establishing social and temporary connections, characteristic of the largest of the metropolises.

To continue with the reflection on the space occupied by the graphic territorially in a context of democratization of information (geo-referenced) we could establish a classification of the drawing according to its object. But, and this is the important thing, it is with the drawing (whatever) that we are able to establish a sort of references and order the managed databases. Any drawings must be positioned (inevitably) to face the reality by ordering a series of databases of codified information that attempts to convey (and this is key) a sort of previously defined intention: there is no graphic without intent, since one's own way of understanding the world in a graphic form necessarily involves a series of resignations latent in the coding (always incomplete) reality. In addition, and as we have already seen, we are working with drawings of an existing or imagined reality. We can use this databases coding system to represent and express things; from the most materialistic facts to (following in the footsteps of Bauman [4]) liquids, i.e., influences, impacts and narratives, as well as the range of data that the material space is often associated with (temporary references, historical,... etc.).

\section{Containers}

With this theoretical basis of argumentation, we can move on to talk about the following containers, paradigms of a way to graph the city, territory and, by extension, the architecture and the contemporary society.

\subsection{Container 1: geographic information systems}

The processing of georeferenced information has never had such an accurate and extensive and, what is more important, so accessible a database before. Numerous institutes, websites and communities have generated such a wide collection of information that the fact of studying and sorting them out graphically (with a GIS program or without it) represents an original way (unpublished) to develop knowledge.

\subsection{Container 2: photogrammetry}

Using the camera as if it were a drawing instrument, photogrammetry software uses a database derived from reality: the photograph themselves. With them as a basis, it firstly creates a cloud of qualified points (colour + position), on which to further build the three-dimensional model. Photogrammetry, useful primarily in the direction of reality-drawing (and not vice versa), is the more accurate way to encode the constructed reality. As we have previously pointed out, the scalar limits of any technique are diffuse, and photogrammetry, far from being limited to the scale of the building, is the technique with which three-dimensional maps and whole digital cities have been built (Google Earth maps are an eloquent example). 


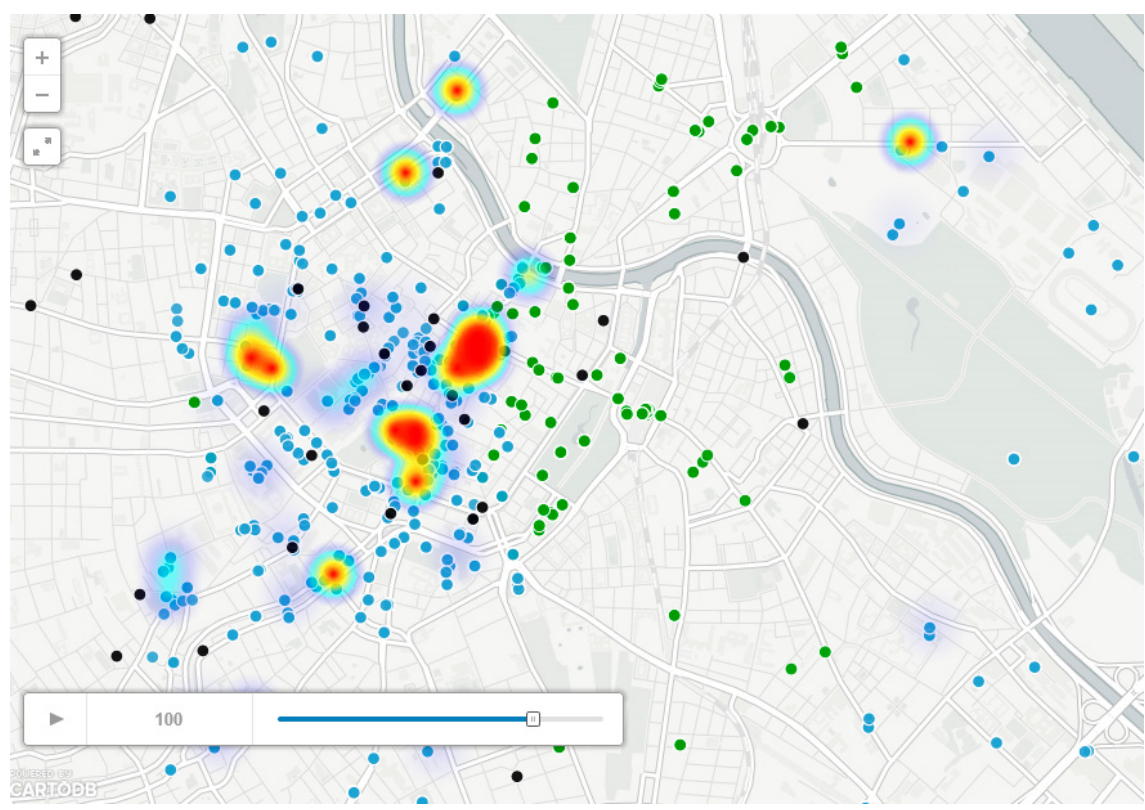

Figure 1: Example of GIS by Jesús López Baeza (student).

\subsection{Container 3: digital three-dimensional modelling}

Used in both directions, the one from the built reality to the drawing (document of the same) as well as the one that links the drawn project with a reality to be built, digital modelling represents the most efficient way to actively codify an existing reality or imagined. The most important difference with photogrammetry is the degree of accuracy achieved, or, which means the same, the use (in a context of modelling) of the ideal forms of representation, such as points, lines and planes. Vectoring drawing, i.e. mathematical coding thereof, acquires, in such drawings, a fundamental relevance.

\subsection{Container 4: building information modelling}

Designed for the scale that defines the building itself, BIM (Building Information Modeling) systems represent a way of understanding the complex reality that must be controlled by architecture in a comprehensive manner. Facilities, structure, materials and space (among others) are treated, analysed and, therefore, drawn, simultaneously. Currently, BIM systems also deal with relations between the buildings (which involves: installations, maintenance, materiality, etc.), i.e., that they are defining new ways of drawing the city.

\subsection{Container 5: other mapping tools (digital and not)}

The complexity (for its unmanageability) of graphics today in the architectural field forces us to create a fifth container, less specific, to locate not only hybrid situations between the four previous containers but, for example, the new (and still 
not significantly associated) graphics. The digital medium not only allows us to combine and implement external variables prior to the graphic context (for example time) but, also, they have been a novel way of projecting and understanding architecture: when in an analogue drawing, the pencil is graphite, and in a cloud of points the pencil is the camera, in a digital environment (and, for example parametric) the pencil becomes a series of codes (first of computer language and, then, of ones and zeros) representing those graphics that we end up seeing in the form of pixels on a screen as a support.

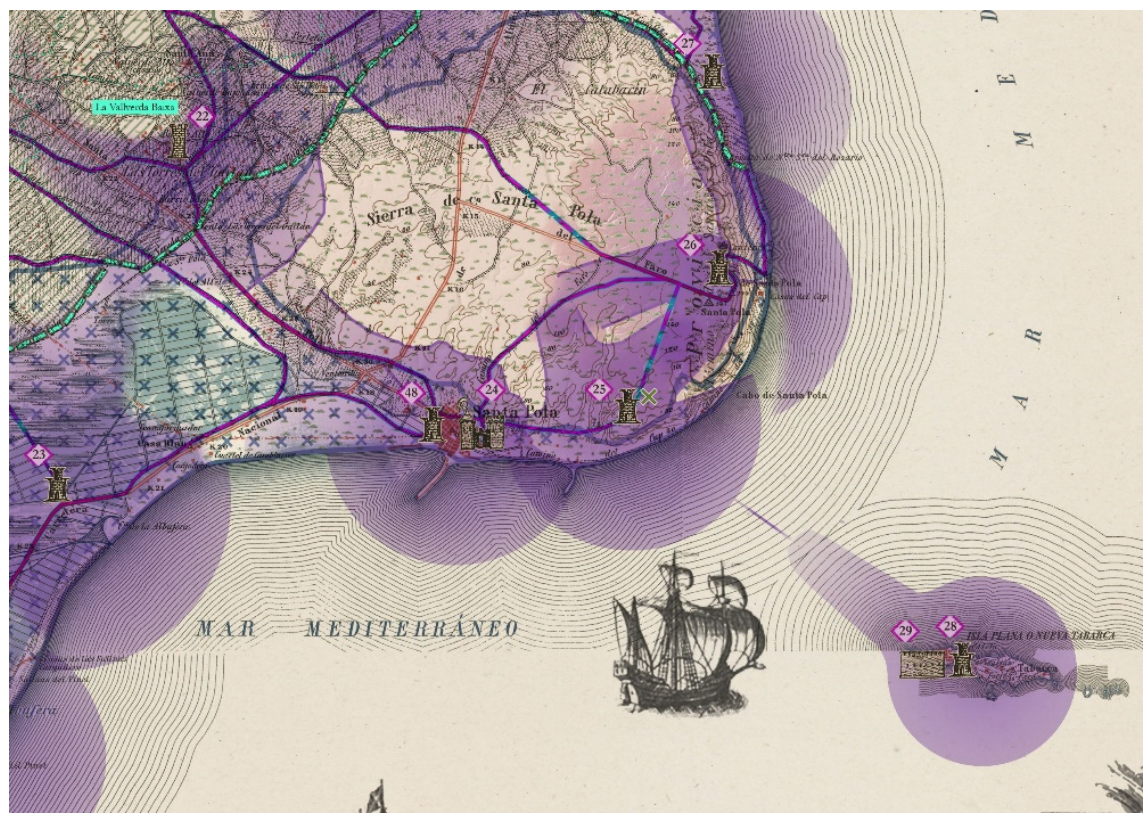

Figure 2: Example of other mapping tools by Jesús Cases Navarro (student).

\section{Analysis}

Then, and in order to apply the previously argued points, we will proceed to analyse and compare different drawings of the city, reeling off the series of resignations that come into play with each one and, but as well for this reason, the direction in which they intend to develop its (occasionally suggestive) narrative speech.

\subsection{Examples of traditional drawing}

We can start with the analysis, from a strictly graphical point of view, of this series of drawings of the 19th century from different municipalities of the province of Alicante. As we can see in all of them, the drawing technique is applied on an initially empty content base to end up making this amendment which we call drawing. Document for history. The artist encodes two things, the analysis of the 
situation and the proposal of the same. This uses a technique (available at the time of completion), a neutral stand (both can be the base) and their own skills and competences around the graphic.

For example, in the case of the urban reform map of Jalon, 1849, by Carbonell and Francisco Abad, we can see how the city is understood as a group of figures (blocks of buildings) on a neutral background (urban space, rural space or a river). The proposal (or part of the city projected) is a drawing in several colours, while the pre-existence is in a pinkish tone. The tremendously limited graphic language is, in this way, simple, crystal clear. The few lines speak eloquently to order, or better said, organize, the built space and to control it. The church, the squares and the precise disposition around a series of axes show no space for dispersion: a drawing as a tool of its time.

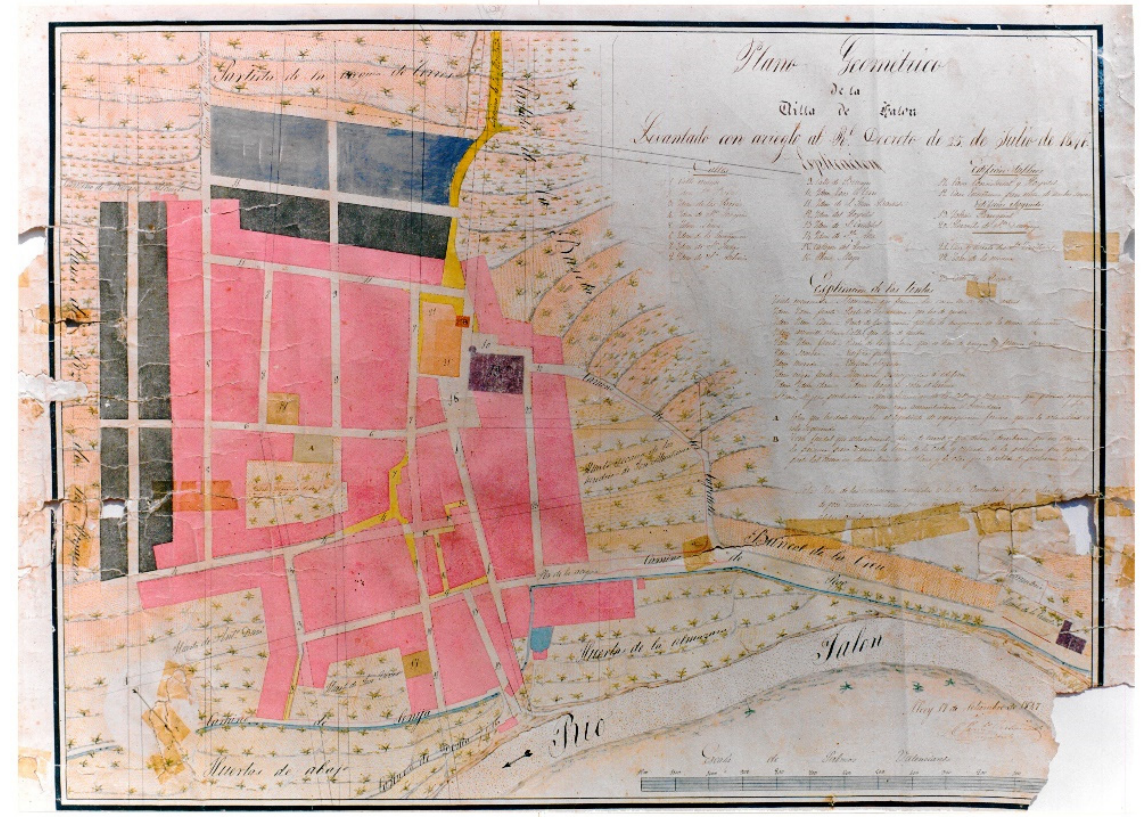

Figure 3: The urban reform map of Jalon, 1849, by Carbonell and Francisco Abad.

The urban reform map of Jalon, 1849, by Carbonell and Francisco Abad, is a beautiful example of the support (physical, not digital) and graphic (fruit of the technique) being witnesses of a journey in time. The symbolism, colours, and graphic coding are, after all, modified by the folds of the paper consequence of its use by readers and as well the weather conditions, which we could get as awards that times grant to it.. Unlike the digital maps, made mostly using and combining mapped geo references and graphic information, this drawing is made in the traditional autographic manner (designed and hand-made), i.e. physically modifying the basis with the help of various specific tools. The simplicity and virtuosity of the technique, but, also, the beginning of the drawing, that has been 
created from a stand that does not have any type of information on it, create beautiful documents but, at the same time, they are extremely practical and limited. Information encoding, the city to be analysed and the city proposed, the symbols used and, in short, all the graphics that are developed, move in a straight line and bluntly towards the end to which they owe their existence: drawings as tools, but, and for this reason, small irreplaceable works of art.

\subsection{Examples of contemporary graphs}

Never again will we be able to make plans in the traditional way (by physically modifying the base in the same way as before (for example, following the illustrative examples, in the 19th century). This is firstly because, even when using the same materials, our education differs notably from the exquisite, but radically different, way of graphing of the (engineers or architects) draftsmen of olden times. That would be a conscious resignation to the digital world (and therefore also a dialogue). In this sense we say that contemporary graphic representations of the city pose a conscious analogue renunciation. Never before now have there been as many means, as many tools and as much information as we have today. In addition, we have another more cyclical fact that has to do with the obsolescence of the software through which we access the digital world. The set of programs is so large and varies so quickly that it is impossible to be blind to the fact that, as important as the series of choices posed by the contemporary graphics are, will be the series of resignations that it inevitably involves implies.

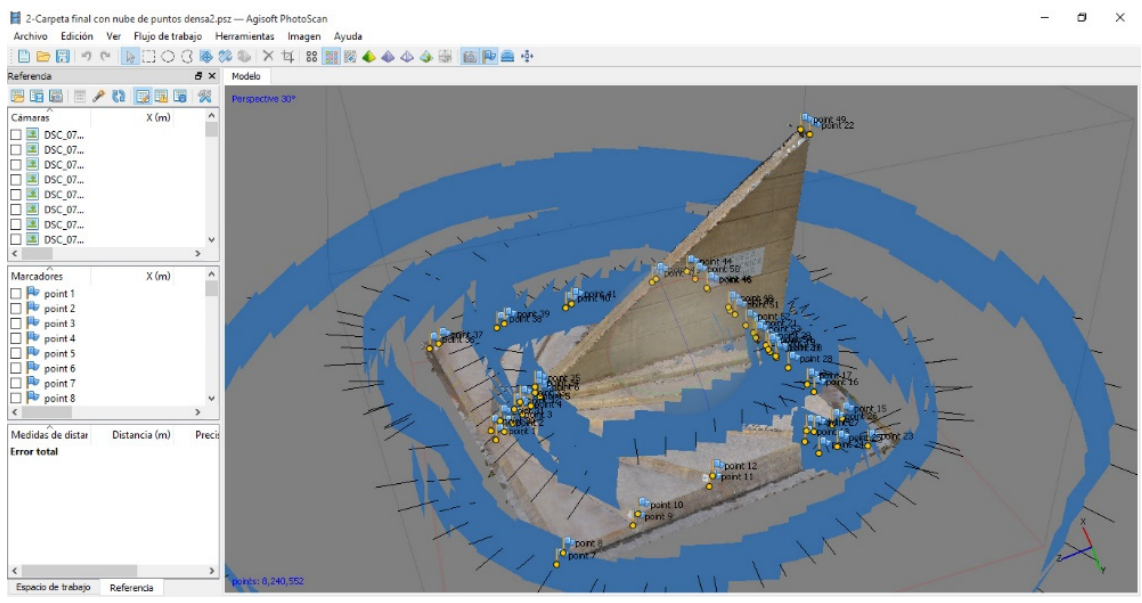

Figure 4: Example of photogrammetry.

Any of the contemporary and graphical examples previously mentioned (GIS, photogrammetry, modelling, or BIM) contains by implication a series of resignations and choices and, before the first line is drawn, begins to define them. Not only has the base been disconnected from the drawing, but this (the election of its nature) implies a certain way of facing the coding that involves the drawing. 


\section{Final discussion}

As already noted in the hypothesis, the spelling (contemporary or not) far exceeds the representation of the physical fact. The drawing and its elements keep running (thanks to the reader) holistically (according to Berguer [5]) and propose a sort of reality (the one of the drawing), which regards the time factor as very important and not just as the cause of the aging of the support. In this way, the contemporary maps underline a feature of drawing in general (analytical or proposal): the space in time will be as important as representing the physical space (e.g. cities), according to the doctrine of Tufte [6], will be the representation of the impact, the affinities and the social (human) aspect. The spatial vision, allowing understanding of the three-dimensional space from the encodings and simplifications made in the traditional two-dimensional drawings, shares the limelight with temporary vision, not only by the referred set of ultra-material realities represented by the drawing, but also, because the new graphics allow the difficulty of capturing three dimensions onto a two-dimensional paper to be avoided. The digital world has enabled us to realize, from three-dimensional mapping, what the importance of the time vision of synthesizing realities (existing or imagined) is: vision.

\section{Conclusions}

We can list the conclusions according to previous classifications:

1. Temporality: the importance, in a contemporary context of architectural drawing, of the temporal vision is similar to that of the spatial vision. The challenge of understanding a three-dimensional element with a twodimensional one is the same as understanding the movement (and change) as a parameter to be encoded by the drawing.

2. Contemporary drawing: the main issue of the contemporary graphic expression is contained in the selection of the information (with which knowledge is produced), the technique itself and the programs used.

3. Graphic criteria: so, in order to properly assess any kind of representation of complex urban reality, we shall be attending not only to what the drawing proposes (its how and its what) but the implied intention with which it develops (its why) and the available possibilities. This is in the way in which the ancient drawings (along with their inseparable support) are understood as priceless documents: they treasure (in addition to the information that originated them) a way of doing, anchored in time.

\section{References}

[1] Ascher, François. Los nuevos principios del urbanismo. El fin de las ciudades no está a la orden del día, Editorial Alianza. Madrid, 2005 [orig. 2001]

[2] Prigogine, Ilya; Stengers, Isabelle. La nueva Alianza. La metamorfosis de la ciencia (1979) Alianza Editorial S.A., Madrid, 1983

[3] Ricoeur, Paul. Tiempo y narración (1985) Ediciones Cristiandad, Madrid, 1987 
[4] Bauman, Zygmunt. Modernidad Líquida (2000) Fondo de Cultura Económica de Argentina, 2004

[5] Berguer, J. (1960) La apariencia de las cosas. Editorial Gustavo Gili, Barcelona, 2014

[6] Tufte, Edward Rolf. Envisioning Information (1990) Graphics Press LLC, U.S.A., 2006 